\title{
The Relation of Foot Morphology to Performance in Three Vertical Jumping Tasks
}

\author{
Relación entre la Morfología del Pie y el Rendimiento en Tres Saltos Verticales
}

\author{
Sánchez-Ramírez, Celso ${ }^{1,2}$; Aguado, Xavier $^{3}$; Hormazábal-Aguayo, Ignacio ${ }^{1}$ \& Alarcón, Eduardo Ed,5 $^{4}$
}

SÁNCHEZ-RAMÍREZ, C.; AGUADO, X.; HORMAZÁBAL-AGUAYO, I.; ALARCÓN, E. The relation of foot morphology to performance in three vertical jumping tasks. Int. J. Morphol., 38(3):545-551, 2020.

SUMMARY: The objective of this research is to relate the performance in three vertical jump events with morphological variables of the foot and stature. A total of 177 practitioners of 12 sporting events aged $24.5 \pm 8.0$ years, with $71.01 \pm 13.00 \mathrm{~kg}$ of body mass, $1.71 \pm 0.09 \mathrm{~m}$ height, and BMI of $24.29 \pm 3.24 \mathrm{~kg} \cdot \mathrm{m}^{-2}$ were evaluated with an anthropometer in terms of foot length (FL), forefoot width $(\mathrm{FW})$, navicular height $(\mathrm{NH})$, and hindfoot width (HW). These variables were normalized to the height of the subjects. From the footprint record the arch index (AI) was obtained, which indicates the morphology of the medial longitudinal foot arch (MLFA). Performance was evaluated in three vertical jump events: countermovement jump (CMJ), squat jump (SJ), and drop jump (DJ), recording the height reached. FL, FW and HW show a weak positive correlation $(r<0.4 ; \mathrm{p}<0.05)$ with the heights achieved in the three types of jump. The stature is strongly associated with FL, FW and HW ( $r=0.8 ; r=0.7$ and $r=0.6$; respectively; $<<0.05)$ and with the height in CMJ, SJ, and DJ $(\mathrm{r}=0.37 ; \mathrm{r}=0.41$ and $\mathrm{r}=0.32$, respectively, $\mathrm{p}<0.05)$. The only normalized morphological foot variable that maintained consistency in the correlations analysis was the normalized foot length (NFL) with $\mathrm{CMJ}(\mathrm{r}=0.2, \mathrm{p}<0,05)$. The subjects whose left foot length was equivalent to $14 \%$ of the stature jumped $27.94 \pm 6.63 \mathrm{~cm}$, those with $15 \%$ jumped $30.96 \pm 7.4 \mathrm{~cm}$, and those with $16 \%$ jumped $31.03 \pm 7.8 \mathrm{~cm}$. FL, FW, HW, and stature are moderately correlated with performance in vertical jump events. However, after discarding the stature of the subjects, only the foot length maintained its relation with performance in CMJ.

KEY WORDS: Vertical Jump; Foot arch; Performance; Anatomy.

\section{INTRODUCTION}

The morphological characteristics of the foot present a wide variability among individuals, which have been related to environmental factors such as practicing sports according Sánchez et al. (2017). Morphological factors have been related to the kind of sport practiced by the subjects, finding, for example, that sprinters have a shorter lever arm at the insertion of the calcaneous tendon (Lee \& Piazza, 2009) and a longer metatarsal bone length (Tanaka et al., 2017) compared to sedentary subjects. Furthermore, anthropometric measurements such as foot length, hallux length, relative heel distances, among others (van Werkhoven \& Piazza, 2017), have been related to motor tasks like jump height, finding significant relations with some of them. Foot length, forefoot width, and hindfoot width (McPoil et al.,
2009) have been associated with footprint support surface and footprint pressure during walking, finding high correlations with statistical significance. Geladas et al. (2005) found a significant correlation between foot length and performance in a 100-meter free-style swimming event.

The medial longitudinal footprint arch (MLFA) has been another morphological variable that has been associated with motor performance. Delgado-Abellán et al. (2012), found modifications of the MLFA height after training sessions with continuous and interval-type exercises, and Berdejo-del-Fresno et al. (2013), describe modifications produced according to the kind of sports activity practiced by the subjects.

\footnotetext{
${ }^{1}$ Escuela de Ciencias de la Actividad Física, Facultad de Ciencias Médicas, Universidad de Santiago de Chile, Santiago, Chile.

${ }^{2}$ Instituto de Ciencias del Deporte, Facultad de Salud, Universidad Santo Tomás, Santiago, Chile.

${ }^{3}$ Laboratorio de Biomecánica, Universidad de Castilla-La Mancha, España.

${ }^{4}$ Escuela de Medicina, Facultad de Ciencias Médicas, Universidad de Santiago de Chile, Santiago, Chile.

${ }^{5}$ Departamento de Ciencias Químicas y Biológicas - Universidad Bernardo O’Higgins, Santiago, Chile.

FUNDING: This research was funded by the Departamento de Investigaciones Científicas y Tecnológicas, Universidad de Santiago de Chile, Project 0151623RC_OP.
} 
The above shows that the practice of physical exercise and sports is a factor that can affect foot morphology. However, -and except for the recent study of van Werkhoven \& Piazza made with ten individuals, which found a correlation between toe length and lateral heel distance-, no studies have been made relating the morphological variables of the foot with performance in jumping events, as a way of standardizing the expected performance.

From the above, the objective of the present research is to relate the performance reached in jumping events with normalized foot morphological variables and stature.

\section{MATERIAL AND METHOD}

Participants. The sample was composed of 177 subjects who voluntarily participated in the study, signing an informed consent form prepared according to the guidelines of the Ethics Committee of the Universidad de Santiago de Chile (Ethical Report No. 577 of 2015). The sample's subjects participated freely in the study, and they were part of a cohort of sports competitors representing the Universidad de Santiago de Chile. Those who were part of the university's competing teams at least during the last six months and practiced at least six hours per week were included. Those who had some acute ankle and/or foot injury were excluded.

Data collection. The information related to training habits and sports history, as well as health aspects of the foot and ankle was obtained from a questionnaire that the subjects filled out immediately after signing the informed consent. Body weight was obtained from the subjects in underwear. The height and weight were determined with a digital balance and an anthropometer (Seca 220, Germany). From the above results the body mass index (BMI).

To avoid altering the results due to activities that the subjects carried out before their arrival at the laboratory, they remained seated at rest for $5 \mathrm{~min}$. They then got on a level table and were asked to take an upright and relaxed bipedal posture with the arms hanging on the sides of the body. The location of the feet was marked by a line drawn on the evaluation table that allowed the feet to be kept about $10 \mathrm{~cm}$ apart. In this position, the evaluator made the measurements with an analog 300-mm Vernier caliper (Veto, E5002009, Chile) with a precision of one tenth of a millimeter.

Foot length (FL) was measured between the rearmost heel point and the foremost point of the longest toe -which can be the first or the second toe-. The forefoot width (FW) was taken as the distance between the medial point of the first metatarsophalangeal joint and the most lateral fifth metatarsophalangeal joint. The hindfoot width (HW) was obtained by measuring the maximum width of the calcaneum, placing the anthropometer parallel to the horizontal plane. The navicular height $(\mathrm{NH})$ was obtained by marking the skin with a 3-mm diameter pencil point at the lowest point of the tubercle of the navicular bone. After this step, with the anthropometer ruler perpendicular to the floor, the distance between the mark made and the surface was measured.

With the aim of comparing the dimensions between subjects of different heights, the variables were normalized. The normalized foot length (NFL) was obtained by dividing the FL by the subject's stature. The normalized forefoot width (NFW), the normalized width of the hindfoot (NHW), and the normalized navicular height $(\mathrm{NNH})$ were calculated by dividing their value by the FL. The relation existing between FW and HW (HW/FW) was also calculated with the purpose of identifying the triangular shape of the foot.

The MLFA morphology was measured by the study of the footprint impression, obtained by photopodoscopy. The subjects got on a metal and glass podoscope, and based on the protocol of Ribeiro et al. (2006), the footprint was photographed with a 14.2 megapixel digital camera (Samsung ST65, China) without zoom and at a focal distance of $43 \mathrm{~cm}$ directly on the glass.

The photopodoscopic analysis was made using the specific AreaCalc software for the calculation of footprint areas developed by Elvira et al. (2008). The MLFA classification was made by means of the Arch Index (AI) (Cavanagh \& Rodgers, 1987). The values proposed by their creators were used to classify the height of the arch: Pes cavus $\mathrm{AI} \leq 0.21$; normal foot $0.21<\mathrm{AI}<0.26$, and flat foot $\mathrm{AI} \geq 0.26$. Sánchez et al., showed that these values were appropriate for this type of population.

In addition to the above tests, the jumping ability was evaluated by means of three vertical jump events applied in the Bosco test: squat jump (SJ), drop jump (DJ), and countermovement jump (CMJ). To measure them, use was made of a platform (Axon Jump S, Argentina) with six cells, connected to a personal computer with installed software. In the case of the DJ, and in order to not modify the execution technique of most subjects, a $40-\mathrm{cm}$ high box was used.

Although there are no major differences, it was defined that all the events had to be performed barefoot to discard shoes as a factor (Koyama \& Yamauchi, 2018). Although the sportspersons already knew the SJ, CMJ, and DJ jumps and they performed them as part of their training, an explanation was given to each participant, as well as a 
generic warmup consisting of running at a self-determined speed for 6 min. Three attempts were made for each event to ensure that the execution technique was the right one and the intensity was maximum. Once the jumping technique was executed correctly, three attempts were made for each jump and the best record was used for the statistical analysis. The order of execution of the jumps was SJ, CMJ, and DJ.

The data analysis was made using the GraphPad Prism, version 6, software. The Kolmogorov-Smirnov test was applied to determine the normality of the data distribution in each of the continuous variables. The descriptive statistics is expressed as the mean and the standard deviation. The Spearman $r$ coefficient was used for the analysis correlations when dealing with nonparametric variables, and the Pearson $r$ when dealing with parametric variables. The data of both feet were recorded and analyzed. The correlations were considered significant when $\mathrm{p}<0.05$.

\section{RESULTS}

The sample consisted of 125 men and 52 women aged $24.5 \pm 8.0$ years, with $71.01 \pm 13.00 \mathrm{~kg}$ of body weight, a height of $1.71 \pm 0.09 \mathrm{~m}$, and a BMI of $24.29 \pm 3.24 \mathrm{~kg} \cdot \mathrm{m}^{-2}$.

The subjects practiced 12 sports events, with track and field, football, and judo as the most frequent ones, making up $50.85 \%$ of the sample. The detailed distribution per sport event is given in Table I.

Table I. Distribution of subjects per sports event.

\begin{tabular}{lcc}
\hline \multicolumn{1}{c}{ Sport } & n & \% \\
\hline Track and field & 38 & 21,47 \\
Football & 34 & 19.21 \\
Judo & 18 & 10.17 \\
Karate & 17 & 9.60 \\
Weightlifting & 15 & 8.47 \\
Basketball & 14 & 7.91 \\
Swimming & 9 & 5.08 \\
Table tennis & 8 & 4.52 \\
Taekwondo & 8 & 4.52 \\
Volleyball & 8 & 4.52 \\
Tennis & 5 & 2.82 \\
Handball & 3 & 1.69 \\
\hline
\end{tabular}

Table II shows the descriptive values obtained in three evaluated jump events. It is seen that the following set of values is obtained: $\mathrm{CMJ}>\mathrm{SJ}>\mathrm{DJ}$, where $\mathrm{CMJ}$ presents mean values around $0.30 \mathrm{~m}, \mathrm{SJ}$ around $0.28 \mathrm{~m}$, and DJ around $0.23 \mathrm{~m}$. The dispersion values of the data are approximately $7 \mathrm{~cm}$ in the three types of jumps.
Table II. Values obtained in the three vertical jump events.

\begin{tabular}{lccc}
\hline & CMJ & SJ & DJ \\
\hline Jump height (m) & 0.30 & 0.28 & 0.23 \\
Mean deviation & 7.39 & 6.83 & 6.88 \\
Range (m) & $0.15-0.54$ & $0.10-0.52$ & $0.08-0.40$ \\
\hline \multicolumn{2}{l}{ CMJ: Counter Movement Jump, SJ: Squat Jump, DJ: Drop Jump. }
\end{tabular}

Table III shows the descriptive statistics of the morphological variables. The mean values found are 255 $\mathrm{mm}$ for FL; $100 \mathrm{~mm}$ for $\mathrm{FW} ; 63 \mathrm{~mm}$ for $\mathrm{HW}$, and $36 \mathrm{~mm}$ for $\mathrm{NH}$. Regarding the normalized variables, it was found that the FL of both feet corresponds to $15 \%$ of the subjects' height, the FW corresponds to $39 \%$ of FL, HW to $25 \%$ of FL, and NH to $14 \%$ in the left foot and $15 \%$ in the right foot. HW is equivalent to $63 \%$ of FW. From the analysis of the footprint the AI was calculated, finding mean values of 0.21 and 0.22 corresponding to a normal foot. There is symmetry in the values of both feet.

Stature is strongly associated with FL $(\mathrm{r}=0.8$, $\mathrm{p}<0.0001)$, FW $(\mathrm{r}=0.7, \mathrm{p}<0.0001)$ and $\mathrm{HW}(\mathrm{r}=0.6$, $\mathrm{p}<0.0001)$, and less with $\mathrm{NH}(\mathrm{r}=0.4$ left foot and $\mathrm{r}=0.3$ right foot, $\mathrm{p}<0.0001)$. Stature is also associated with the height reached in the three types of jumps, but with higher values with CMJ ( $r=0.37, \mathrm{p}<0.0001)$ and $\mathrm{SJ}(\mathrm{r}=0.41, \mathrm{p}<0.0001)$. Since stature is related to the morphological variables and these, in turn, are related to the jumping performance, the correlations were calculated with normalized variables, discarding the stature.

Table III. Values of normalized morphological variables.

\begin{tabular}{lcc}
\hline & $\begin{array}{c}\text { LEFT FOOT } \\
\mathbf{n}=\mathbf{1 7 7}\end{array}$ & $\begin{array}{c}\text { RIGHT FOOT } \\
\mathbf{n}=\mathbf{1 7 7}\end{array}$ \\
\hline NFL (FL/Stature) & $0.15 \pm 0.01$ & $0.15 \pm 0.01$ \\
NFW (FW/FL) & $0.39 \pm 0.02$ & $0.39 \pm 0.02$ \\
NHW (HW/FL) & $0.25 \pm 0.02$ & $0.25 \pm 0.02$ \\
NNH (NH/FL) & $0.14 \pm 0.03$ & $0.15 \pm 0.03$ \\
HW/FW ratio & $0.63 \pm 0.06$ & $0.63 \pm 0.04$ \\
AI & $0.21 \pm 0.07$ & $0.22 \pm 0.07$ \\
\hline
\end{tabular}

FL: Foot length; FW: Forefoot width; HW: Hindfoot width; NH: Navicular height; NFL: Normalized foot length; NFW: normalized forefoot width; NHW: Normalized hindfoot width; NNH: Normalized navicular height; AI: Arch index.

Table IV shows the interaction of the normalized variables with the vertical jump height reached in the evaluated events. It is seen that NFW, NHW and HW/FW have no correlation with the jump heights, except for a small significant correlation $(r=0.14 ; p=0.03)$ between right NFW and DJ. Variable AI maintains small significant correlations with the left foot and CMJ, DJ, and SJ ( $\mathrm{r}=0.16, \mathrm{p}=0.0347 ; \mathrm{r}=0.19$, $\mathrm{p}=0.0053$, and $\mathrm{r}=0.13, \mathrm{p}=0.0427$ respectively); and the right foot with SJ $(r=0.15, p=0.0255)$ and $\mathrm{DJ}(\mathrm{r}=0.13, \mathrm{p}=0.0399)$. 
Table IV. Correlations between normalized morphological variables and jump height.

\begin{tabular}{|c|c|c|c|c|}
\hline & $\begin{array}{c}\text { CMJ } \\
\text { height }\end{array}$ & $\begin{array}{c}\text { SJ } \\
\text { height }\end{array}$ & $\begin{array}{c}\text { DJ } \\
\text { height }\end{array}$ & Stature \\
\hline \multirow{2}{*}{ Stature } & 0.37 & 0.41 & 0.32 & \multirow[b]{2}{*}{-} \\
\hline & $<0.0001 *$ & $<0.0001^{*}$ & $<0.0001 *$ & \\
\hline \multirow{2}{*}{ NFL Left } & 0.24 & 0.15 & 0.15 & 0.07 \\
\hline & $0.0014^{*}$ & $0.0209 *$ & $0.0227 *$ & 0.1895 \\
\hline \multirow{2}{*}{ NFL Right } & 0.20 & 0.13 & 0.10 & 0.01 \\
\hline & $0.0070^{*}$ & $0.0408 *$ & 0.1001 & 0.4369 \\
\hline \multirow{2}{*}{ NFW Left } & -0.02 & -0.01 & 0.04 & -0.1189 \\
\hline & 0.7701 & 0.4414 & 0.3039 & 0.1148 \\
\hline \multirow{2}{*}{ NFW Right } & 0.07 & 0.07 & 0.14 & -0.0546 \\
\hline & 0.3614 & 0.1852 & $0.0308 *$ & 0.4701 \\
\hline \multirow{2}{*}{ NHW Left } & -0.07 & -0.08 & -0.04 & -0.0857 \\
\hline & 0.3415 & 0.1457 & 0.3045 & 0.2565 \\
\hline \multirow{2}{*}{ NHW Right } & -0.06 & -0.12 & -0.01 & -0.0238 \\
\hline & 0.3966 & 0.0642 & 0.4665 & 0.8550 \\
\hline \multirow{2}{*}{ NNH Left } & 0.08 & 0.04 & -0.07 & 0.0729 \\
\hline & 0.2885 & 0.3029 & 0.1868 & 0.3345 \\
\hline \multirow{2}{*}{ NNH Right } & 0.07 & 0.05 & -0.08 & 0.0493 \\
\hline & 0.3920 & 0.2743 & 0.1364 & 0.5143 \\
\hline \multirow{2}{*}{ HW/FW Left } & -0.08 & -0.08 & -0.07 & -0.0003 \\
\hline & 0.2924 & 0.1326 & 0.1751 & 0.9967 \\
\hline \multirow{2}{*}{ HW/FW Right } & -0.12 & -0.12 & -0.12 & 0.0408 \\
\hline & 0.1200 & 0.0636 & 0.0638 & 0.5895 \\
\hline \multirow{2}{*}{ AI Left } & 0.16 & 0.13 & 0.19 & -0.03 \\
\hline & $0.0347 *$ & $0.0427 *$ & $0.0053 *$ & 0.3274 \\
\hline \multirow{2}{*}{ AI Right } & 0.14 & 0.15 & 0.13 & -0.03 \\
\hline & 0.0641 & $0.0255^{*}$ & $0.0399 *$ & 0.3263 \\
\hline
\end{tabular}

Significant $\mathrm{p}$ results are marked with an asterisk $(*)$. NFL: Normalized foot length; NFW: Normalized forefoot width; NHW: Normalized hindfoot width; NNH Normalized navicular height; AI: Arch Index. CMJ: Counter Movement Jump, SJ: Squat Jump, Dj: Drop Jump.

From Table IV it can also be seen that the only normalized morphological variable of the foot which maintained its consistency in the correlations analysis was NFL with CMJ. It maintains $r$ values greater than 0.2 with statistical significance. The graph of this correlation is shown in Figures 1A and 1B, which show the left and the right foot, respectively.

Since CMJ was the variable that got the highest $r$ values, an estimation is presented of the jump height that this type of population may present as a function of its NFL. Figure 2A gives the results for the left foot, which shows that the subjects who have an NFL=0.14 jump $26.48 \pm 6.1 \mathrm{~cm}$, those who have an NFL=0.15 jump $30.75 \pm 7.2 \mathrm{~cm}$, and those whose $\mathrm{NFL}=0.16$ jump $33.24 \pm 8.2 \mathrm{~cm}$. A significant difference was found between the 0.14 and 0.15 groups ( $\mathrm{p}=0.02)$ and the 0.14 and 0.16 groups $(\mathrm{p}=0.00)$.

Figure 2B shows the results for the right foot, indicating that the subjects who have an NFL=0.14 jump $27.94 \pm 6.63 \mathrm{~cm}$; those whose $\mathrm{NFL}=0.15$ jump $30.96 \pm 7.4 \mathrm{~cm}$; and those whose NFL $=0.16$ jump $31.03 \pm 7.8 \mathrm{~cm}$. In this case there were no significant differences between the groups.
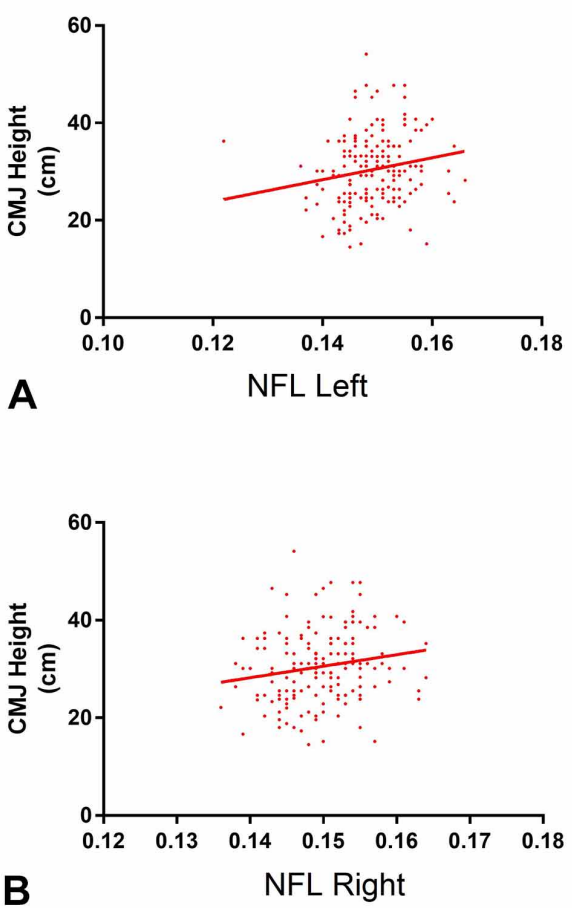

Fig. 1. Correlation between the values of NFL and jump height reached by the sample's subjects for the left foot sample (A) and right foot sample (B).
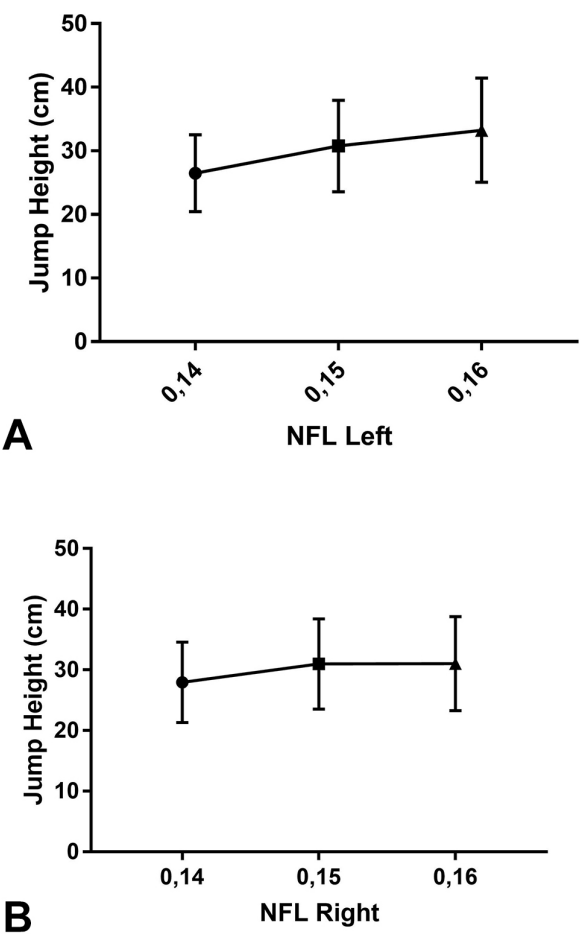

Fig. 2. Jump values reached by the sample according to the NFL. A: left foot; B: right foot. 


\section{DISCUSSION}

It should be stressed that the sample for this study was chosen for convenience, with the purpose of getting a transversal vision of the characteristics of interest. It is understood that this design does not allow extrapolating the results to other populations. The number of subjects studied is interesting considering that according to the National Survey of Physical Activity and Sports Habits among the population aged 18 years and older (Ministerio del Deporte, 2016), only $31.8 \%$ of Chile's population carries out physical activities regularly, and that of this percentage, $1.7 \%$ practice it in their study place-population to which this study belongs-, giving the result of a universe of 95,005 persons at the national level. According to the calculation of the sample size, the sample is representative, with a $95 \%$ confidence interval and a margin of error of $7 \%$.

An interesting aspect of this study is that a pattern of positive correlations was found between the morphological variables and jump height, in spite of the particular morphological adaptations of each sport (Bayios et al., 2006; Berdejo-del-Fresno et al.). This study involved sportspeople from 12 different sports activities. However, the fact that the values point to a weak correlation must not be avoided.

A positive and significant correlation was found between jump height and stature, with values of 0.3 to 0.4 for the three types of jumps. In this respect there are contradicting visions. For example, Sheppard et al. (2008) also found correlations among volleyball practitioners, but with higher values: 0.77 for CMJ and 0.66 for DJ, and in another study also carried out with volleyball players, no significant relation was found between stature and performance in CMJ (Aouadi et al., 2012).

In relation to the above, in this study the morphological variables FL, FW, and HW present medium to high correlation with stature, the same as reported in other populations (Ashizawa et al., 1997), in contrast with $\mathrm{NH}$, which presents low correlation with stature, indicating that this morphological variable is related to lower extent with the body's lengths. Along this same line, analyzing the correlation of the morphological variables with the performance achieved in the jumping event, $\mathrm{NH}$ was the only variable that did not correlate with DJ. We hypothesize that this difference occurred because this variable correlated to a lower extent with stature, and it is also influenced by other factors such as the strength of the eversion muscles and muscle tone of the tibialis posterior and the adductor hallucis (Aydog et al., 2005; McKeon et al., 2015).
During the development of this study, since it was not shown that the foot dimensions by themselves had greater influence on jump performance than the stature, it was decided to normalize the variables. The same statistical analysis was made, showing that NFL maintained low, but significant $r$ values, perhaps suggesting that to some extent, subjects having relatively longer feet have better performance in the jump event. This result is in agreement with Davis et al. (2006), who found that foot length accounts for $8 \%$ of the vertical variability displacement in CMJ.

The association existing between foot length and performance in explosive force events like jumps has been found in several previous studies. For example, Baxter et al., report that sprinters have longer metatarsals than a group of subjects who were not athletes, results similar to those reported by Lee \& Piazza, who conclude that sprinters have longer toes. Scholz et al. (2008), on the other hand, found a strong association between running economy and torque in the ankle joint; they also found a significant correlation between running economy and foot length, and this might explain its association with mechanical advantages in the lever arm of the calcaneous tendon.

A recent study de van Werkhoven \& Piazza indicated that the jump height in DJ is correlated with toe length and with the lateral foot length, but it is not correlated with FL or with stature. This relation existing between FL and performance in explosive force events may be explained by findings of the study of Rolian et al. (2009), where it was attempted to explain the advantages of modern human beings of having shorter phalanges than Australopithecus. There, it is shown that having a shorter forefoot appears as a morphological solution that reduces the momentum arms over the metatarsophalangeal joints This aspect has an incidence on an increase of the economy of locomotion by causing lower requirements on the long flexor muscles of the toes and of the hallux. However, this configuration presents opposite effects for actions that require a large production of force in a short period of time, as jumps, where the high momentum arms produced are transformed into an advantage, supporting the correlation between NFL and jump height.

The flexor hallucis longus and the flexor digitorum longus muscles are also important in the maintenance of the MLFA (Kapandji, 2010). A weak correlation was found between NFL and AI, since the longer the foot, the flatter is the MLFA. With respect to the previous paragraph, it can be theorized that the toe flexor muscles, during contact with the ground, are more elongated in a flattened MLFA, and this may contribute to a greater accumulation of elastic energy that would finally result in achieving a greater jump height. 
This research contributed to increase the knowledge available with respect to the relation between foot morphology and motor performance when studying the relations between anthropometric and performance variables. It was defined that foot length, forefoot width, hindfoot width, and stature are moderately correlated with performance in vertical jump events. However, by discarding the subjects' stature, only the foot length maintained its relation to performance in CMJ together with the height of the medial longitudinal foot arch.

For future work, it is suggested to study the relation between the different bone segments of the foot, such as the metatarsal and heel length, the perimeter of the forefoot, among others, as a way of integrating in greater depth the morphology of the foot with its functionality. Since correlations found were weak, it would be interesting to carry out a multifactorial study to determine the percentage of influence of the NFL and AI variables on the height of the jump.

Also, and as future patterns, it is suggested to study subjects practicing the same sports activity with the purpose of establishing the morphological adaptations that its practice produces. Furthermore, looking into the use of other methodologies that allow studying in greater depth the morphological milestones in 2 and 3 dimensions, such as geometric morphometry. This issue was already approached as a descriptive (Domjanic et al., 2013) and correlational study (Stankovic' et al., 2018), and it would be interesting to continue along that line.

SÁNCHEZ-RAMÍREZ, C.; AGUADO, X.; HORMAZÁBALAGUAYO, I. \& ALARCÓN, E. Relación entre la morfología del pie y el rendimiento en tres saltos verticales. Int. J. Morphol., 38(3):545-551, 2020.

RESUMEN: El objetivo de esta investigación fue relacionar el rendimiento en salto vertical con variables morfológicas del pie y estatura. 177 practicantes de 12 disciplinas deportivas de 24,5 $\pm 8,0$ años; 71,01 $\pm 13,00 \mathrm{~kg} ; 1,71 \pm 0,09 \mathrm{~m}$, e IMC de 24,29 $\pm 3,24$ $\mathrm{kg} \bullet \mathrm{m}^{-2}$ fueron evaluados con un antropómetro obteniendo longitud de pie (FL), ancho de antepié (FW), altura navicular $(\mathrm{NH})$ y ancho de retropié (HW). Estas variables fueron normalizadas a la estatura. Se midió la huella plantar obteniendo el índice del arco (AI), el cual indica la morfología del arco plantar longitudinal medial (MLFA). El rendimiento fue evaluado en tres pruebas de salto: salto con contramovimiento (CMJ), sentadilla con salto (SJ) y salto desde caída (DJ), registrando la altura alcanzada. FL, FW y HW mostraron una débil correlación positiva $(r<0,4$; $p<0,05)$ con la altura alcanzada en los tres saltos. La estatura se asocia con FL, FW y HW $(r=0,8 ; r=0,7$ y r=0,6; respectivamente; $p<0,05)$ y con la altura en CMJ, SJ y DJ (r=0,37; r=0,41 y r=0,32, respectivamente, $\mathrm{p}<0,05)$. La única variable normalizada del pie que mantuvo con- sistencia en el análisis de correlaciones fue la longitud del pie normalizada (NFL) con CMJ ( $\mathrm{r}=0,2 ; \mathrm{p}<0,05)$. Los sujetos cuyo pie tiene una longitud equivalente al $14 \%$ de la estatura saltaron 27,94 $\pm 6,63 \mathrm{~cm}$, los que equivalen al $15 \%$ saltaron $30,96 \pm 7,4 \mathrm{~cm}$ y quienes tuvieron un pie equivalente a un $16 \%$ de la estatura saltaron $31,03 \pm 7,8 \mathrm{~cm}$. FL, FW, HW y la estatura se correlacionan moderadamente con el rendimiento en salto vertical. Sin embargo, después de descartar la estatura de los sujetos, solamente la longitud del pie mantiene su relación con el rendimiento en CMJ.

PALABRAS CLAVE: Salto vertical ; Arco plantar; Rendimiento; Anatomía.

\section{REFERENCES}

Aouadi, R.; Jlid, M. C.; Khalifa, R.; Hermassi, S.; Chelly, M. S.; Van Den Tillaar, R. \& Gabbett, T. Association of anthropometric qualities with vertical jump performance in elite male volleyball players. J. Sports Med. Phys. Fitness, 52(1):11-7, 2012.

Ashizawa, K.; Kumakura, C.; Kusumoto, A. \& Narasaki, S. Relative foot size and shape to general body size in Javanese, Filipinas and Japanese with special reference to habitual footwear types. Ann. Hum. Biol., 24(2):117-29, 1997

Aydog, S. T.; Ozçakar, L.; Tetik, O.; Demirel, H. A.; Hasçelik, Z. \& Doral, M. N. Relation Between foot arch index and ankle strength in elite gymnasts: a preliminary study. Br. J. Sports Med., 39(3):e13, 2005.

Bayios, I. A.; Bergeles, N. K.; Apostolidis, N. G.; Noutsos, K. S. \& Koskolou, M. D. Anthropometric, body composition and somatotype differences of Greek elite female basketball, volleyball and handball players. J. Sports Med. Phys. Fitness, 46(2):271-80, 2006.

Berdejo-del-Fresno, D.; Lara Sánchez, A. J.; Martínez-López, E. J.; Cachón Zagalaz, J. \& Lara-Diéguez, S. Alteraciones de la huella plantar en función de la actividad física realizada. Rev. Int. Med. Cienc. Act. Fís. Deporte, 13(49):19-39, 2013.

Cavanagh, P. R. \& Rodgers, M. M. The arch index: a useful measure from footprints. J. Biomech., 20(5):547-51, 1987.

Davis, D. S.; Bosley, E. E.; Gronell, L. C.; Keeney, S. A.; Rossetti, A. M.; Mancinelli, C. A. \& Petronis, J. J. The relationship of body segment length and vertical jump displacement in recreational athletes. $J$. Strength Cond. Res., 20(1):136-40, 2006.

Delgado-Abellán, L.; Aguado, X.; Jiménez-Ormeño, E.; Mecerreyes, L. \& Alegre, L. M. Efectos del ejercicio continuo e intermitente sobre la huella plantar. Arch. Med. Deporte, 29(148):601-8, 2012.

Domjanic, J.; Fieder, M.; Seidler, H. \& Mitteroecker, P. Geometric morphometric footprint analysis of young women. J. Foot Ankle Res., 6(1):27, 2013

Elvira, J. L. L.; Vera-García, F. J. \& Meana, M. Subtalar joint kinematic correlations with footprint arch index in race walkers. J. Sports Med. Phys. Fitness, 48(2):225-34, 2008.

Geladas, N. D.; Nassis, G. P. \& Pavlicevic, S. Somatic and physical traits affecting sprint swimming performance in young swimmers. Int. J. Sports Med., 26(2):139-44, 2005.

Kapandji, A. I. Fisiología Articular. Vol. II. $6^{\text {th }}$ ed. Madrid, Médica Panamericana, 2010.

Koyama, K. \& Yamauchi, J. Comparison of lower limb kinetics, kinematics and muscle activation during drop jumping under shod and barefoot conditions. J. Biomech., 69:47-53, 2018.

Lee, S. S. M. \& Piazza, S. J. Built for speed: musculoskeletal structure and sprinting ability. J. Exp. Biol., 212(Pt. 22):3700-7, 2009.

McKeon, P. O.; Hertel, J.; Bramble, D. \& Davis, I. The foot core system: a new paradigm for understanding intrinsic foot muscle function. $\mathrm{Br} . J$. Sports Med., 49(5):290, 2015. 
McPoil, T. G.; Vicenzino, B.; Cornwall, M. W. \& Collins, N. Can foot anthropometric measurements predict dynamic plantar surface contact area? J. Foot Ankle Res., 2:28, 2009.

Ministerio del Deporte. Encuesta Nacional de Hábitos de Actividad Física y Deportes en la Población de 18 Años y Más. Santiago de Chile, Ministerio del Deporte, Instituto Nacional de Deportes, Gobierno de Chile, 2016. Available from: http://www.mindep.cl/wp-content/uploads/ $2016 / 07 /$ INFORME-FINAL-ENCUESTA-DEPORTES COMPLETO_.pdf

Ribeiro, A. P.; Trombini-Souza, F.; Iunes, D. H. \& Monte-Raso, V. V. Confiabilidade inter e intra-examinador da fotopodometria e intra-examinador da fotopodoscopia. Rev. Bras. Fisioter, 10(4):4-8, 2006.

Rolian, C.; Lieberman, D. E.; Hamill, J.; Scott, J. W. \& Werbel, W. Walking, running and the evolution of short toes in humans. J. Exp. Biol., 212(Pt. 5):713-21, 2009.

Sánchez, C.; Alarcón, E. \& Morales, H. Morphofunctional foot characteristics of chilean university athletes in ten sports disciplines. Int. J. Morphol., 35(4):1403-8, 2017.

Scholz, M. N.; Bobbert, M. F.; van Soest, A. J.; Clark, J. R. \& van Heerden, J. Running biomechanics: shorter heels, better economy. J. Exp. Biol., 211(Pt. 20):3266-71, 2008.

Sheppard, J. M.; Cronin, J. B.; Gabbett, T. J.; McGuigan, M. R.; Etxebarria N. \& Newton, R. U. Relative importance of strength, power and anthropometric measures to jump performance of elite volleyball players. J. Strength Cond. Res., 22(3):758-65, 2008.

Stankovic', K.; Booth, B. G.; Danckaers, F.; Burg, F. Vermaelen, P.; Duerink, S.; Sijbers, J. \& Huysmans, T. Three-dimensional quantitative analysis of healthy foot shape: a proof of concept study. J. Foot Ankle Res., $11: 8,2018$.

Tanaka, T.; Suga, T.; Otsuka, M.; Misaki, J.; Miyake, Y.; Kudo, S.; Nagano, A. \& Isaka, T. Relationship between the length of the forefoot bones and performance in male sprinters. Scand. J. Med. Sci. Sports, 27(12):1673-80, 2017.

van Werkhoven, H. \& Piazza, S. J. Foot structure is correlated with performance in a single-joint jumping task. J. Biomech., 57:27-31, 2017.
Corresponding author:

Sánchez-Ramírez, Celso

Sophoras 175

Estación Central

Región Metropolitana

Santiago

CHILE

Email: celso.sanchez@usach.cl

Received: 29-10-2019

Accepted: 05-11-2019 